Article

\title{
Design and Development of a Bio-Inspired UHF Sensor for Partial Discharge Detection in Power Transformers
}

\author{
Luiz A. M. M. Nobrega *(D), George V. R. Xavier ${ }^{(D,}$, Marcus V. D. Aquino, Alexandre J. R. Serres, \\ Camila C. R. Albuquerque and Edson G. Costa
}

Department of Electrical Engineering, Universidade Federal de Campina Grande, Aprigio Veloso 882, Campina Grande 58429-900, Brazil; george.xavier@ee.ufcg.edu.br (G.V.R.X.); marcus.aquino@ee.ufcg.edu.br (M.V.D.A.); alexandreserres@dee.ufcg.edu.br (A.J.R.S.); camila.albuquerque@ee.ufcg.edu.br (C.C.R.A.); edson@dee.ufcg.edu.br (E.G.C.)

* Correspondence: luiz.nobrega@ee.ufcg.edu.br

Received: 2 January 2019; Accepted: 31 January 2019; Published: 5 February 2019

\begin{abstract}
In this paper, the design and development of a bio-inspired UHF sensor for partial discharge detection in power transformers is presented. The UHF sensor was developed for external use in dielectric windows of power transformers. For this purpose, a microstrip antenna was designed with a radiating element shape based on the leaf of the Jatropha mollissima (Pohl) Baill plant. Then, an epoxy coating and an aluminium enclosure were developed to protect the antenna against corrosion and to provide mechanical support, external noise immunity, and a lifetime compatibility with power transformers. In order to verify the electrical parameters of the developed sensor, measurements of the gain and the reflection coefficient were performed in an anechoic chamber. Lastly, the antenna sensitivity for denominated partial discharge (PD) detection was compared with the IEC 60270 standard method. For this purpose, simultaneous tests were carried out in a partial discharge generator setup, composed of an oil cell with needle-plane electrodes. The experimental tests demonstrated the effectiveness of the sensor for detecting PD signals with apparent charge values higher than $35 \mathrm{pC}$.
\end{abstract}

Keywords: bio-inspired; partial discharge; antenna; UHF sensor; power transformer; monitoring

\section{Introduction}

Electrical insulation systems are one of the main components of high-voltage equipment. In general, these insulation systems have higher dielectric strength than air, allowing them to support high-voltage levels with a shorter distance between electrodes. In this way, the system becomes more compact, reducing space and costs. However, the insulating material is subjected to high electrical fields, which excites the electrical charges inside the insulation. The acceleration of these charges by the electrical field may cause electron avalanche, in which parts of the insulation become conductive. When this occurs, small internal discharges appear, known as denominated partial discharges (PD). These discharges, although initially of a small magnitude, are by nature an evolutionary process that cause chemical decomposition and material erosion. As a consequence, the damaged area can increase in size and cause the insulation to breakdown. Therefore, damage to the insulation of electrical equipment must be recognized in its initial stages, PD detection being the most common method used for this purpose.

As far as PD detection and measurement mechanisms are concerned, several techniques have been used for monitoring electrical equipment, such as the method defined by the IEC 60279 standard [1] and acoustic [2,3], optical [4,5], and chemical [6] detection methods. In addition, one technique that 
has received attention in the last years uses general UHF sensors to detect, locate, and characterize PD activity [7-14].

Initially, the UHF measurement was used for the diagnosis of a gas insulated substations (GIS) [15], becoming an economically viable online monitoring method for PD measurement [16]. As a result of the consolidation of UHF monitoring in GIS, particularly because of its good immunity to external noise and the possibility of locating defects, in 1997, researchers began to apply the method in power transformers [17]. Since then, countless investigations have been developed, and the applicability of UHF PD measurement in transformers has been promising. Indeed, currently, the Cigre [18] recommends the manufacturing of power transformers with factory adaptation for UHF PD monitoring, whose first models have already been presented in the literature [19].

Among the UHF sensors that can be applied for PD detection, microstrip antennas are highlighted because of some interesting practical features, such as their low cost, ease of installation and manufacture, attractive radiation patterns, and wideband. However, the microstrip antennas with classical radiating element (patch) shapes (such as, rectangles, circles, triangles, squares, and others) designed to operate in the UHF range would assume relatively large dimensions [20-24], limiting their practical application for PD detection in power transformers.

According to References $[25,26]$, the operating frequency of microstrip antennas is directly related to the perimeter of the radiating element. The greater the perimeter, the lower the operating frequency. Therefore, techniques applied in antenna miniaturization mainly seek geometries that maximize the patch perimeter. These optimized geometries can be addressed in the shapes of living beings found in nature, developed in order to provide greater efficiency regarding the ability to survive. Hence, aiming to achieve a better radiating efficiency, bio-inspired antennas use the structure of plants or animals as a basis for their design. Moreover, bio-inspired designs generally present a higher perimeter/area ratio, allowing an antenna size reduction. Furthermore, bio-inspired geometries provide a higher density of current concentrations on the transmission line, resulting in a higher gain than classical microstrip antenna shapes, essential for the detection of low intensity PD pulse signals [27].

Studies involving bio-inspired antennas have been receiving great attention in several fields, such as ultrawideband operation [25], band-stop purposes [28], coplanar waveguide antennas [29], 2G, 3G, and 4G operation [27], and wireless systems [26]. Some studies applied other miniaturizing techniques in the development of UHF sensors for PD detection, such as fractal shapes as well as [30-33] other alternative shapes [34-36]. However, narrow bandwidth sensors were produced, failing in the full coverage of the PD activity frequency range. In contrast, with the simultaneous application of a bio-inspired geometry design and the truncated ground plane bandwidth enhancement technique, it is possible to develop a UHF sensor that presents a compact size (necessary for the application) and with enough bandwidth for the PD detection in power transformers.

In order to contribute to the state-of-the-art techniques in transformer monitoring, this paper presents the design and development of a bio-inspired UHF sensor for PD monitoring of power transformers. The sensor is developed for adaptation in dielectric windows, and for this purpose, an aluminum enclosure was developed in order to protect the antenna against corrosion and to provide mechanical support, external noise immunity, and a lifetime compatibility with power transformers.

This paper is organized as follows: Section 2 presents an overview of PD UHF transformer monitoring. In Section 3, the detailed design of the UHF sensor proposed in this research is described. In Section 4, the experimental tests carried out for validation of the designed UHF sensor are presented, while the discussions and conclusion are presented in Sections 5 and 6, respectively.

\section{UHF Monitoring of Power Transformers}

The UHF monitoring principle is based on the electromagnetic waves radiated by the PD pulse, which has a rise time of less than a nanosecond [37]. The electromagnetic waves emitted by the PD pulse are propagated in all directions with frequencies that vary depending on the phenomenon, type of defect, and propagation material. In power transformers, the radiation typically assumes 
a frequency range from 0 to $1500 \mathrm{MHz}[17,38]$. To exemplify the phenomenon, Figure 1 presents a simulation of a UHF propagation in a power transformer in four different moments. As can be seen, the electromagnetic waves are radiated from the PD source until they reach the equipment tank. In this way, UHF sensors can be installed on the tank of the the equipment to detect, identify, and locate PD sources.

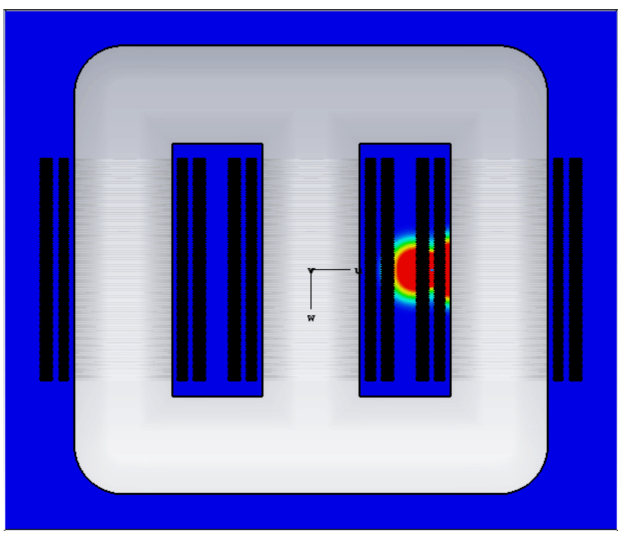

(a) $2.2 \mathrm{~ns}$

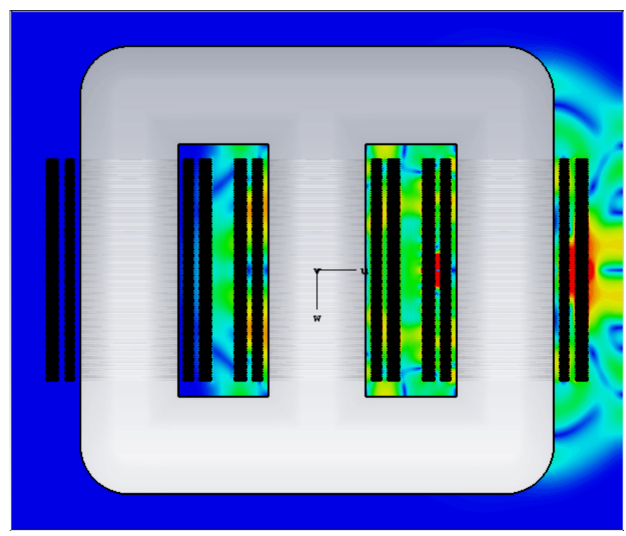

(c) $9.4 \mathrm{~ns}$

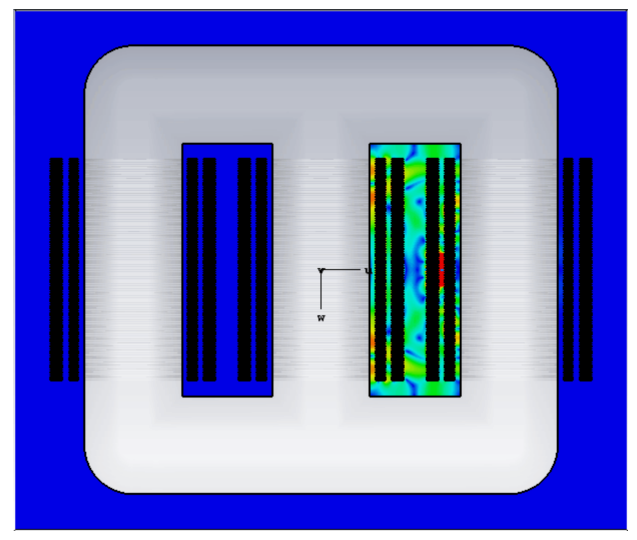

(b) $5.6 \mathrm{~ns}$

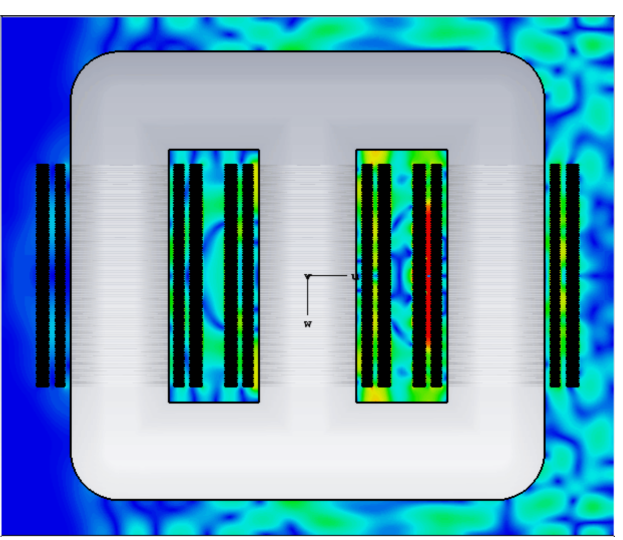

(d) $14.6 \mathrm{~ns}$

Figure 1. Radiation of electromagnetic waves in a power transformer.

The UHF PD monitoring in power transformers has three main advantages. The first one is the high immunity to external noise due to the shielding effect of the transformer tank. The second one is the immunity to detection of corona discharge signals, since these signals do not have appreciable energy at UHF frequencies [39]. The third advantage of the method is its high sensitivity due to the moderately attenuated propagation in the transformer oil [40], in a way that only one sensor is required for the continuous monitoring of the equipment [13] and four sensors for locating the PD sources [10].

For the UHF monitoring of PD in transformers, several types of sensors can be used, being normally classified as internal [41], external [13,14,19], and valve sensors [7,42]. Hereafter, we describe the installation of external sensors for use in dielectric windows, the object of study of this paper.

The external window sensors are installed in apertures in the equipment tank, against dielectric windows retrofitted or constructed for this purpose. Figure 2 presents a cross-section through an inspection hatch with a UHF sensor installed in a dielectric window. As can be observed, it is necessary to insert a dielectric material between the internal part of the transformer and the sensor to allow the electromagnetic waves to find a path to the external environment (where the sensor is located). According to Reference [19], the choice of the dielectric material is not especially critical from the perspective of electromagnetic properties. Mechanical, chemical, and lifetime properties must be 
dominant choice factors. With a suitable mechanic design, the window is not exposed to the external environment and must keep the oil pressure in a normal operational range, being always covered by the sensor or by a protection plate. For the dielectric materials, either polytetrafluoroethylene (PTFE)—which is chemically inert and impermeable to moisture-or several types of epoxy resins can be used [19].

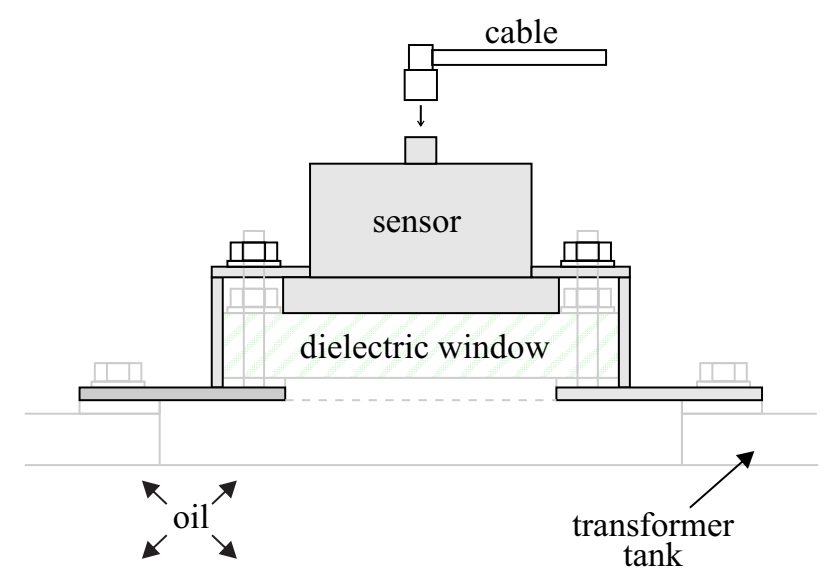

Figure 2. UHF sensor and window assembly on a transformer hatch cover [19].

\section{UHF Sensor Design}

The UHF sensor designed in this research is composed of three main parts: (1) one microstrip antenna with bio-inspired technology, to capture the UHF signal radiated from PD sources; (2) an epoxy coating, which provides the sensor with protection against corrosion, mechanical support, and high temperature tolerance; and (3) an electromagnetic shield, in order to guarantee immunity to external noise. Next, we present the procedures performed to obtain the final version of the developed sensor.

\subsection{Bio-Inspired Microstrip Antenna}

The first step in the development of the sensor is the design and manufacture of the bio-inspired microstrip antenna. For that, the initial design parameters were a central resonance frequency of $900 \mathrm{MHz}$ and a bandwidth of $1200 \mathrm{MHz}$. A FR4 dielectric substrate $\left(\varepsilon_{r}=4.4\right)$ was used with a thickness of $1.6 \mathrm{~mm}$. The shape of the patch antenna was based on the leaf of the Jatropha mollissima (Pohl) Baill plant and the ground plane was truncated along the length of the transmission line to increase the antenna bandwidth [43]. Among the several plant shapes analyzed, the Jatropha mollissima (Pohl) Baill provided a good perimeter/area ratio, since the antenna patch fills a great area within the compact dimensions required for the installation in the dielectric window, and conferred enough bandwidth and gain results for PD detection applications in power transformers as is presented in the coming sections.

In the design of the patch antenna, the perimeter $(p)$ of the bio-inspired geometric shape was calculated in agreement with the lowest resonance frequency $\left(f_{L}\right)$ of PD occurrence $(300 \mathrm{MHz})$ according to Equations (1) and (2) [25]:

$$
\begin{gathered}
\varepsilon_{r e f}=\frac{\varepsilon_{r}+1}{2}+\frac{\varepsilon_{r}-1}{2}\left[1+12 \frac{h}{W}\right]^{-1 / 2}, \text { for } W / h>1, \\
f_{L}(G H z)=300 /\left(p \sqrt{\varepsilon_{r e f}}\right),
\end{gathered}
$$

where $h$ represents the dielectric substrate thickness and $W$ the microstrip width.

In order to obtain an optimized structure in terms of gain, size, and coefficient of reflection, geometric parameter sweeps, such as, width and length of the leaves, as well the distance and opening angle between them were calculated. The final detailed dimensions of the described bio-inspired antenna and the leaf of the Jatropha mollissima (Pohl) Baill plant are summarized in Figure 3. 


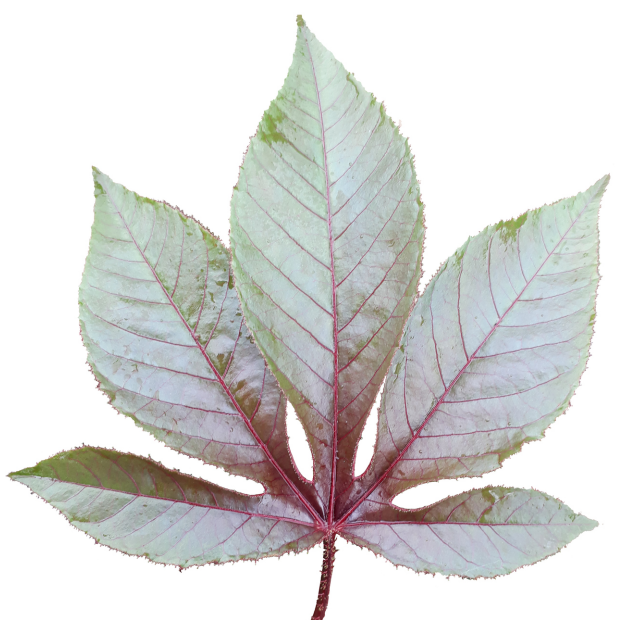

(a)

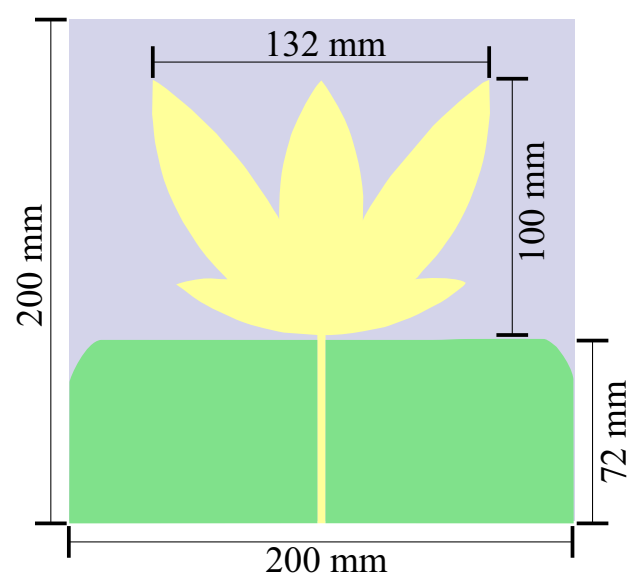

(b)

Figure 3. (a) Graphical representation of the Jatropha mollissima (Pohl) Baill leaf and (b) the designed bio-inspired antenna.

To obtain the main parameters of the antenna, simulations were performed in the high frequency structure simulator (HFSS) from ANSYS. The first simulation result analyzed was the antenna reflection coefficient, as shown in Figure 4.

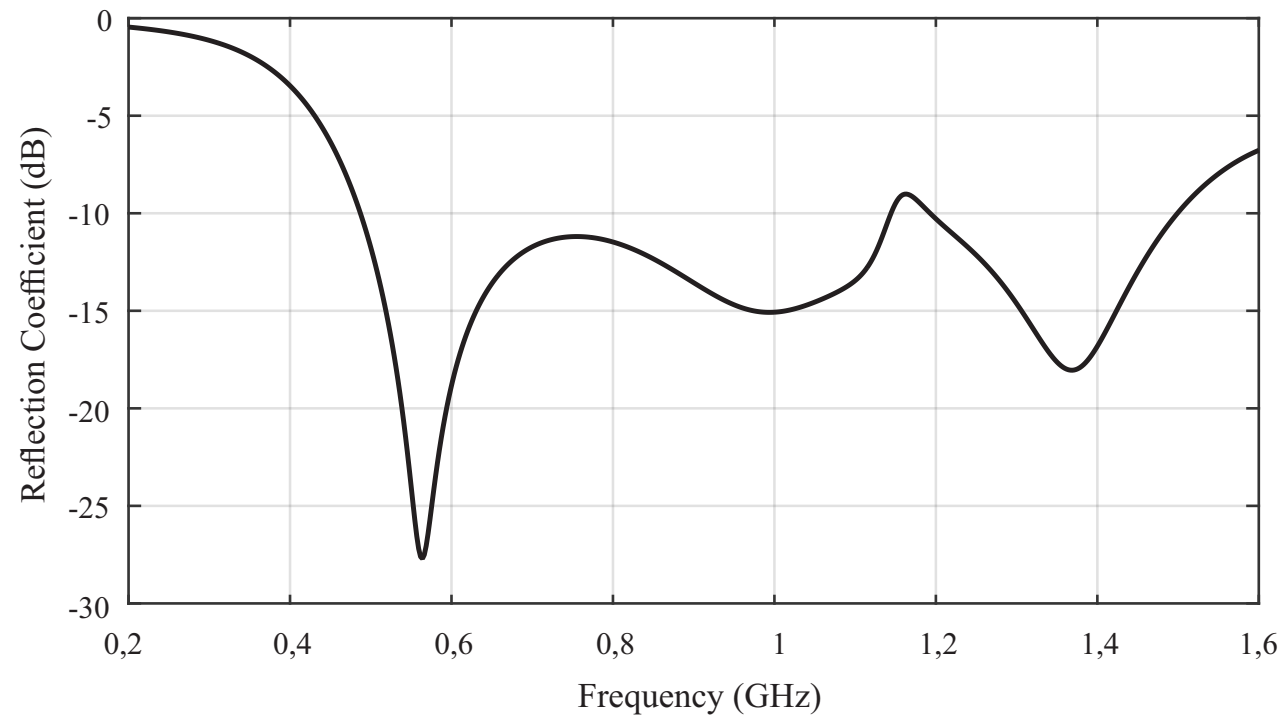

Figure 4. Simulated reflection coefficient for the bio-inspired antenna.

As can be seen in Figure 4, the bio-inspired antenna presented an operating band from 487 to $1145 \mathrm{MHz}$ and 1194 to $1497 \mathrm{MHz}$, with a reflection coefficient less than $-10 \mathrm{~dB}$. Therefore, the bio-inspired antenna was able to provide a satisfactory bandwidth over most of the range of interest for PD detection (300 to $1500 \mathrm{MHz}$ ).

In addition to the reflection coefficient, the antenna radiation pattern and gain for the lower (487 MHz), central (992 MHz), and upper (1497 MHz) frequencies were obtained, as shown in Figures 5 and 6 . From the radiation patterns, it is possible to verify that most of the energy is radiated in the direction of interest for PD detection, corresponding to $0^{\circ}$ in the radiation pattern. The mean gain obtained in the direction of maximum radiation was $2.69 \mathrm{dBi}$. 


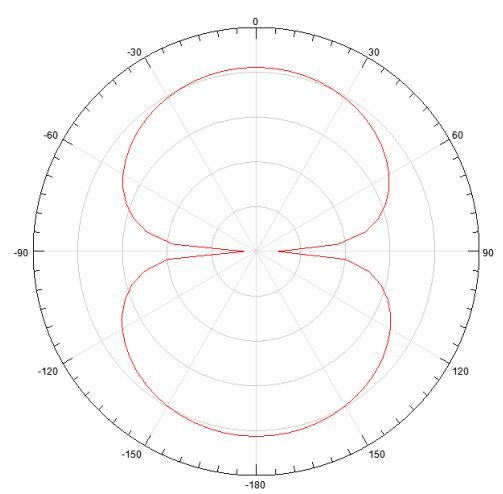

(a)

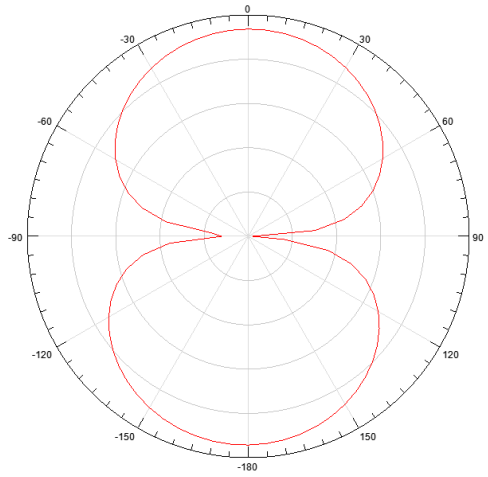

(b)

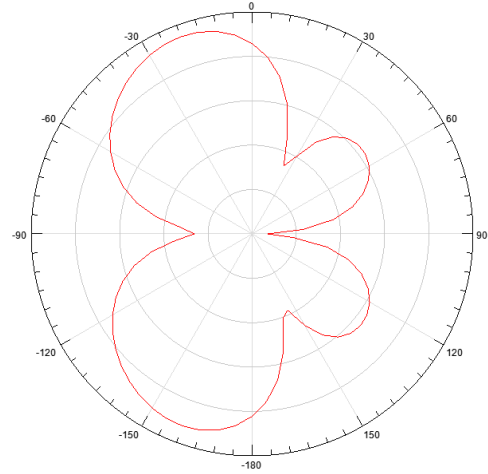

(c)

Figure 5. Antenna radiation pattern for: (a) $487 \mathrm{MHz}$; (b) $992 \mathrm{MHz}$; (c) $1497 \mathrm{MHz}$.

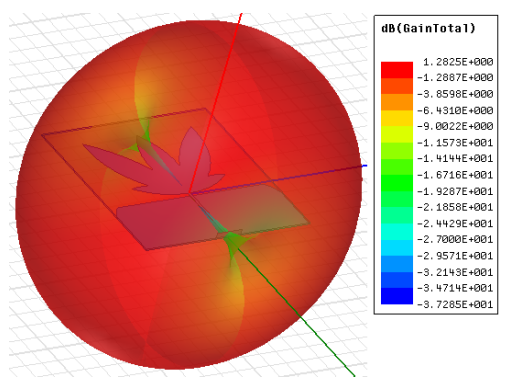

(a)

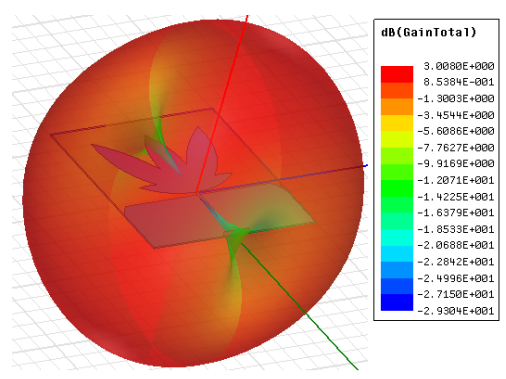

(b)

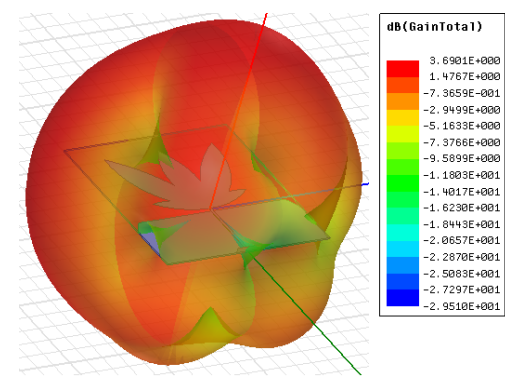

(c)

Figure 6. 3D directive gain pattern for: (a) $487 \mathrm{MHz}$; (b) $992 \mathrm{MHz}$; (c) $1497 \mathrm{MHz}$.

\subsection{Electromagnetic Shield}

Evaluations of the electromagnetic shielding effect on the antenna reflection coefficient were performed in laboratory. For that, the antenna was manufactured in a LPKF ProtoMat S103 circuit board plotter. Then, a metal plate was moved towards the antenna ground plane at fixed distances of $2,4,8$, and $10 \mathrm{~cm}$ and the reflection coefficient was measured for each distance. A photograph of the experimental setup is shown in Figure 7, which used a vector network analyzer (VNA) E5071C $(9 \mathrm{MHz}-8.5 \mathrm{GHz})$ from Keysight Technologies for measurement. The antenna reflection coefficient for each measurement is shown in Figure 8.

From the results, it is observed that the closer the metal structure is to the antenna, the more degenerate the measured reflection coefficient. The best results were obtained with the metal plate at a distance of 8 and $10 \mathrm{~cm}$. In the first scenario, it is possible to verify a reflection coefficient below $-5 \mathrm{~dB}$ in the frequency range of interest. In the second scenario, the effect of the metal plate was negligible, so that the reflection coefficient presented values below $-10 \mathrm{~dB}$ in the range of $600 \mathrm{MHz}$ to $1.5 \mathrm{GHz}$. 


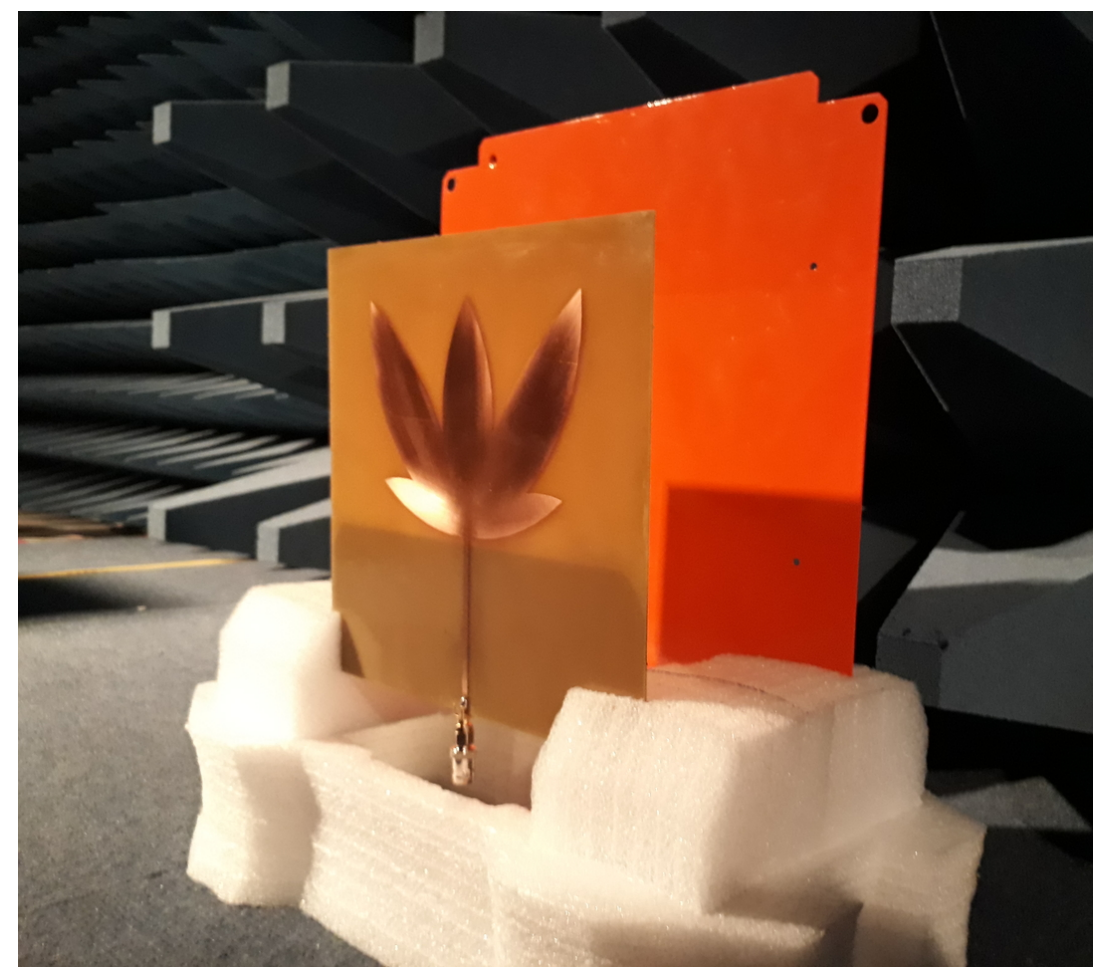

Figure 7. Experimental setup for the electromagnetic shielding test.

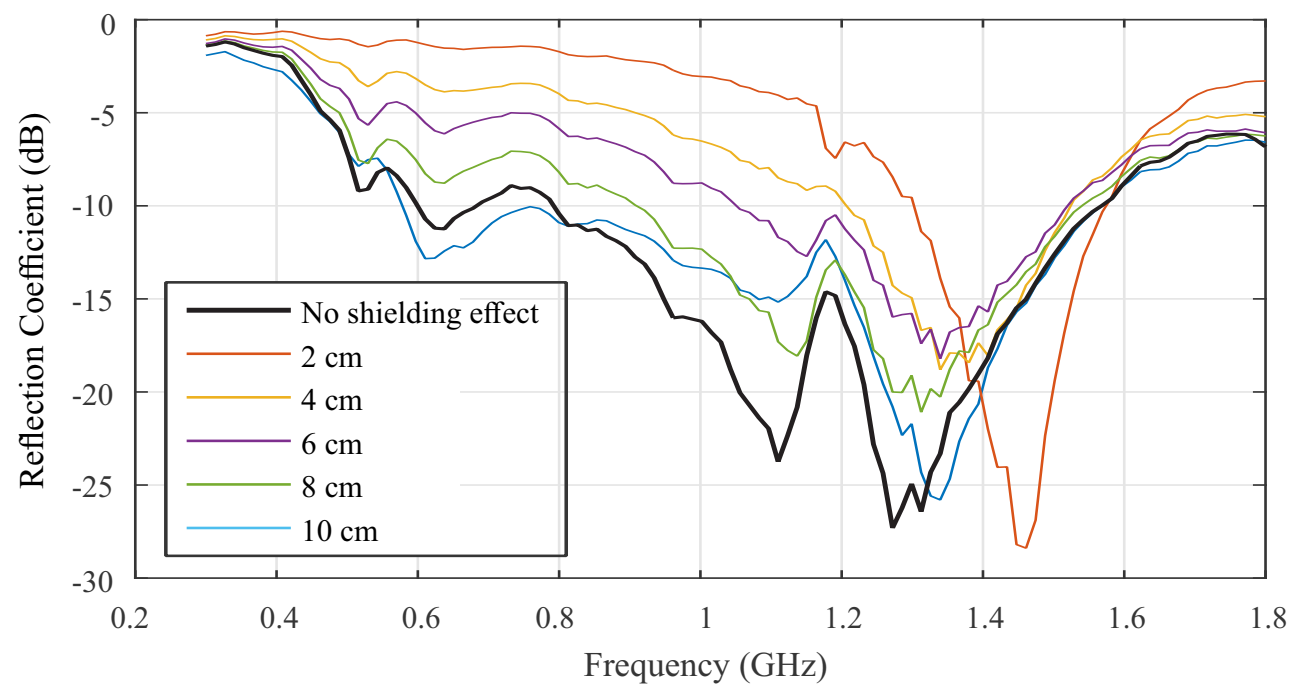

Figure 8. Electromagnetic shielding effect over the bio-inspired reflection coefficient.

\subsection{Proposed UHF Sensor}

After the measurements, the microstrip antenna was encapsulated in epoxy resins with a thickness of $20 \mathrm{~mm}$ to provide protection against corrosion, mechanical support, and a lifetime compatibility with power transformers. Besides that, an aluminum enclosure was produced with an air-gap of $10 \mathrm{~cm}$ between the back of the structure and the antenna ground plane. This distance is necessary to avoid interference, as demonstrated in Section 3.2. Figure 9 shows a photograph of the manufactured UHF sensor, where (a) the radiating element of the bio-inspired antenna; (b) the ground plane on the other side; (c) the aluminum sensor enclosure; and (d) the complete assembly of the UHF sensor are shown. 


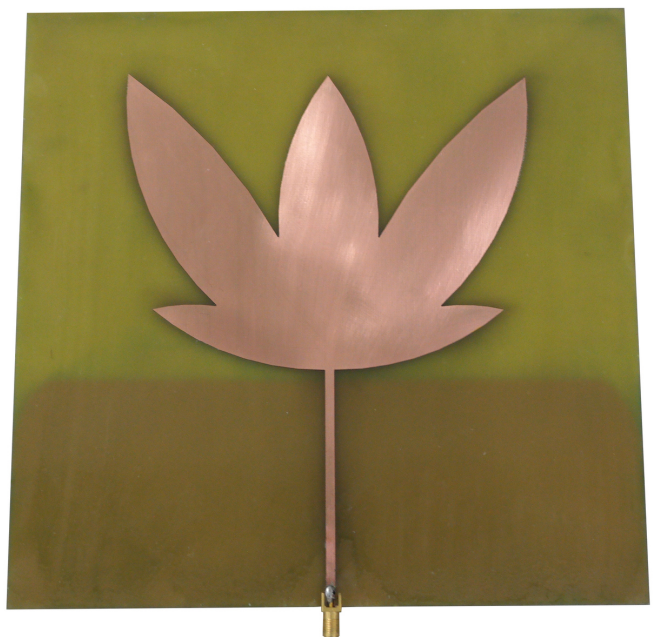

(a)

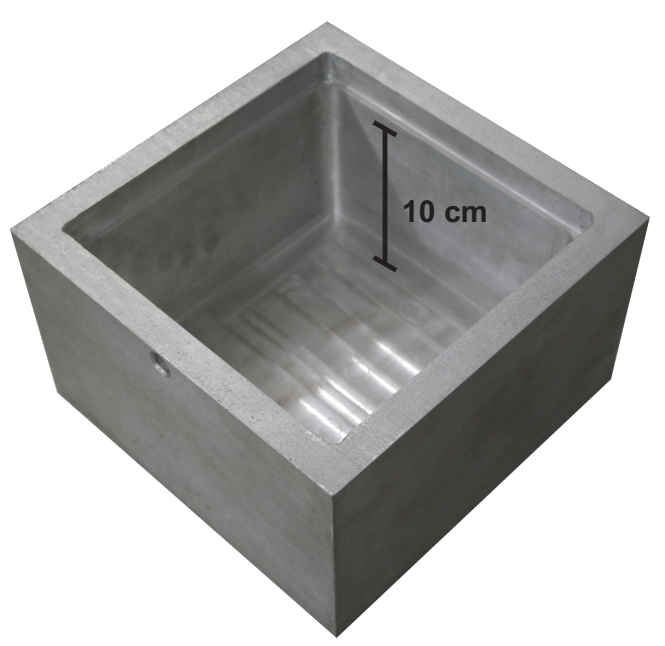

(c)

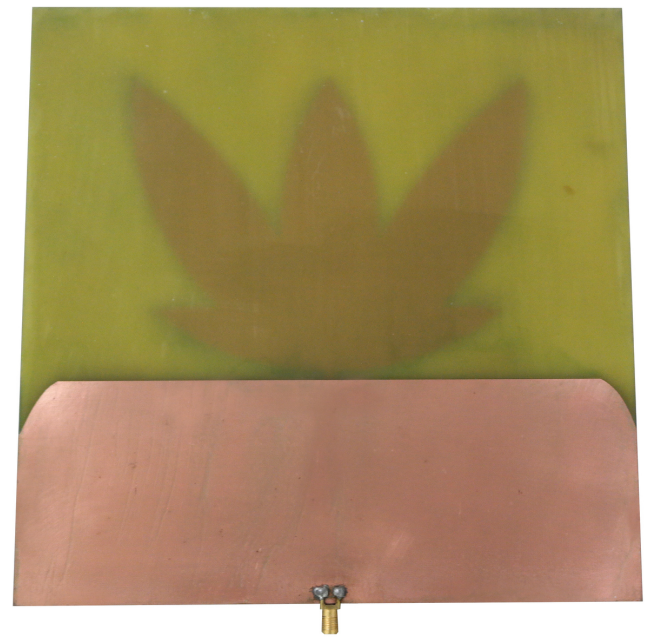

(b)

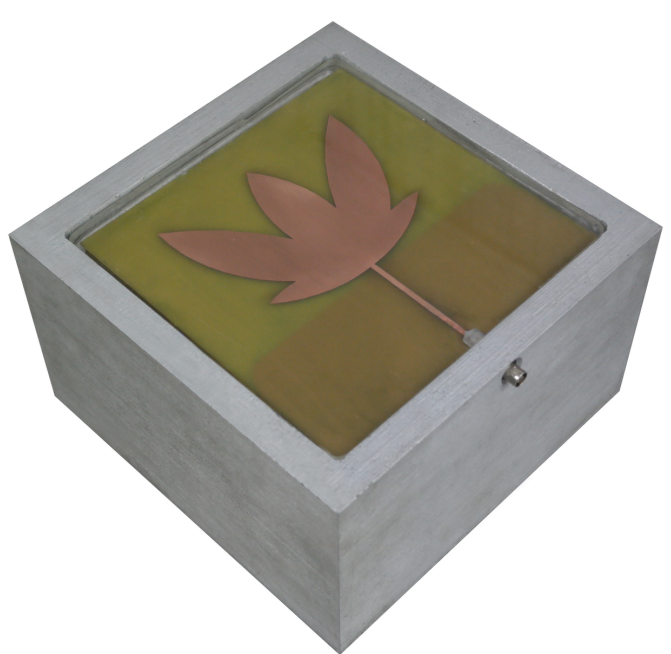

(d)

Figure 9. Components and assembly of the UHF sensor. (a) Radiating element of the bio-inspired antenna. (b) Ground plane on the other side of the antenna. (c) Aluminum sensor enclosure. (d) Complete assembly of the UHF sensor.

\section{Experimental Testing}

For the sensor functionality verification, two sets of measurements were performed. The first one concerns the obtaining of the sensor electrical parameters. The second one was the PD measurement test.

\subsection{Electrical Parameters}

To obtain the main electrical parameters of the sensor, measurements were performed in an anechoic chamber using a VNA E5071C (9 MHz-8.5 GHz) from Keysight Technologies. Initially, the sensor reflection coefficient was obtained, the result is shown in Figure 10. 


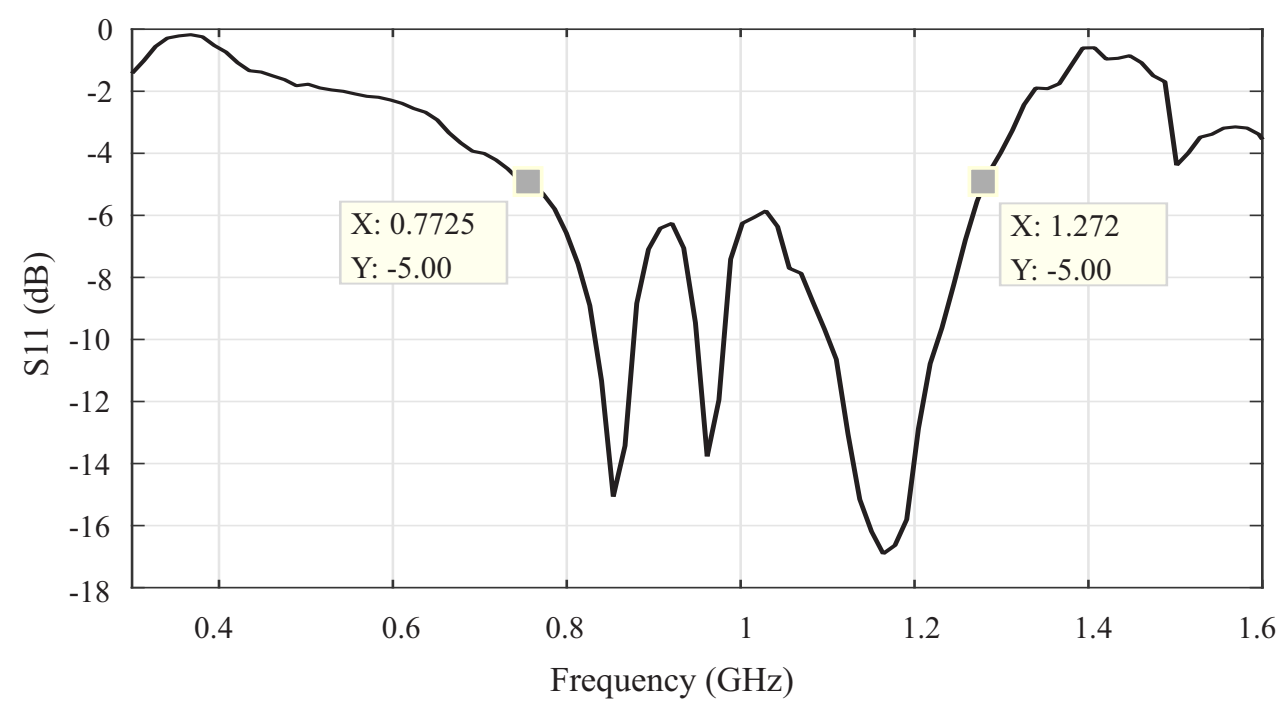

Figure 10. Reflection coefficient of the UHF sensor.

As can be seen in Figure 10, the UHF sensor presented a higher reflection coefficient than the bio-inspired antenna. This result was expected because the UHF sensor aluminum enclosure creates a coupling effect that interferes with the microstrip patch. However, despite the degeneration of the reflection coefficient, the sensor bandwidth can be based on the $-5 \mathrm{~dB}$ limit of the measured $S_{11}$, which represents a transmission of approximately $70 \%$ of the power signal. After these considerations, the sensor operation is observed in the frequency range of 772 to $1272 \mathrm{MHz}$.

The sensor gain was also measured. For that, an Aaronia Hyperlog 30100X was used as the reference antenna, which operates in the frequency range of $400 \mathrm{MHz}$ to $10 \mathrm{GHz}$ with a mean gain of $4.5 \mathrm{dBi}$. The reference antenna and the UHF sensor were positioned in front of each other at a distance (R) of $1.75 \mathrm{~m}$, defined according to the far-field (Fraunhofer) region of the UHF sensor, as illustrated in Figure 11.

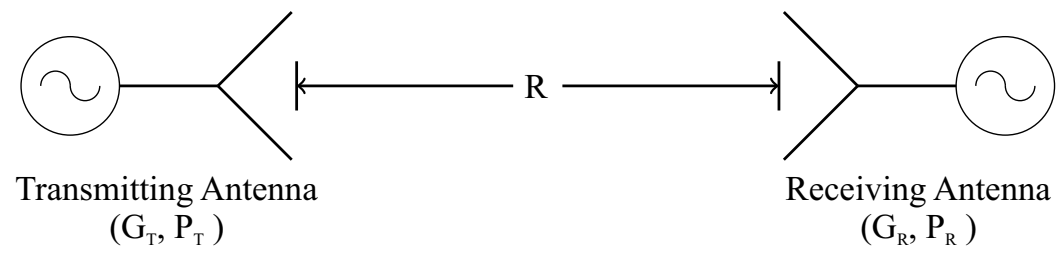

Figure 11. Schematic of the experimental arrangement applied on the gain measurement test.

From the measured values of transmitted and received powers, the gain of the UHF sensor was calculated according to the Friis Transmission Equation [44]:

$$
\left[G_{R}\right]_{d B}=\left[P_{R}\right]_{d B}-\left[P_{T}\right]_{d B}-\left[G_{T}\right]_{d B}-\left[1-\left|\Gamma_{R}\right|^{2}\right]_{d B}-\left[1-\left|\Gamma_{T}\right|^{2}\right]_{d B}+20 \log _{10}\left(\frac{4 \pi R}{\lambda}\right)
$$

where $G_{R}$ and $G_{T}$ are the gains of the reference and the test antenna, respectively, and $P_{R}$ and $P_{T}$ are the measured powers of the reference and the test antenna, respectively. The terms $\Gamma_{R}$ and $\Gamma_{T}$ are the return losses of the reference and the test antenna, respectively. The term $(\lambda / 4 \pi R)^{2}$ is denominated the free-space loss factor, and it takes into account the losses as a result of the spherical spreading of the energy by the antenna. A photograph of the gain measurement setup is shown in Figure 12. 


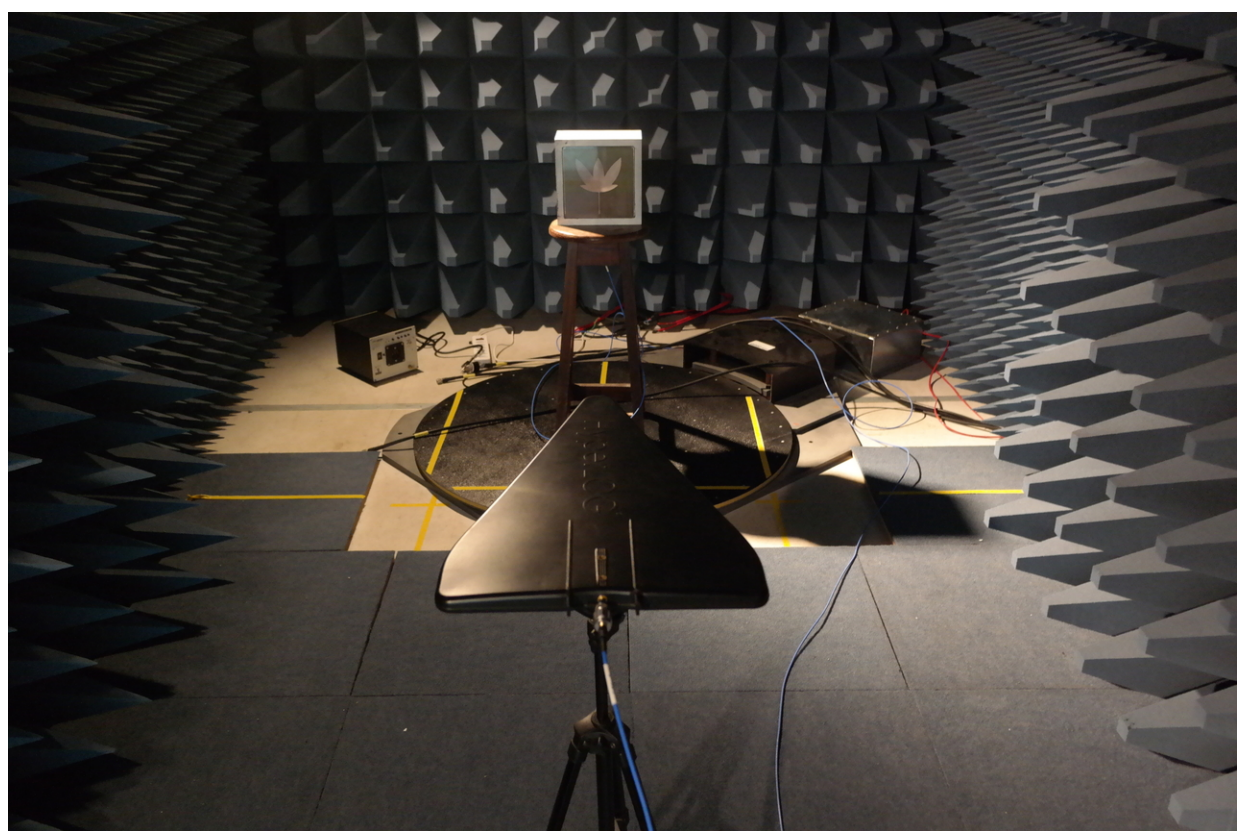

Figure 12. Gain measurement setup.

The first result obtained is the gain of the UHF sensor as a function of the frequency, as shown in Figure 13. It can be observed that the UHF sensor has a positive gain in most parts of the frequency band and a mean gain of $3.89 \mathrm{~dB}$. Previous measurements with UHF antennas demonstrate that a mean gain higher than $2 \mathrm{~dB}$ is already sufficient for the detection of PD signals [45].

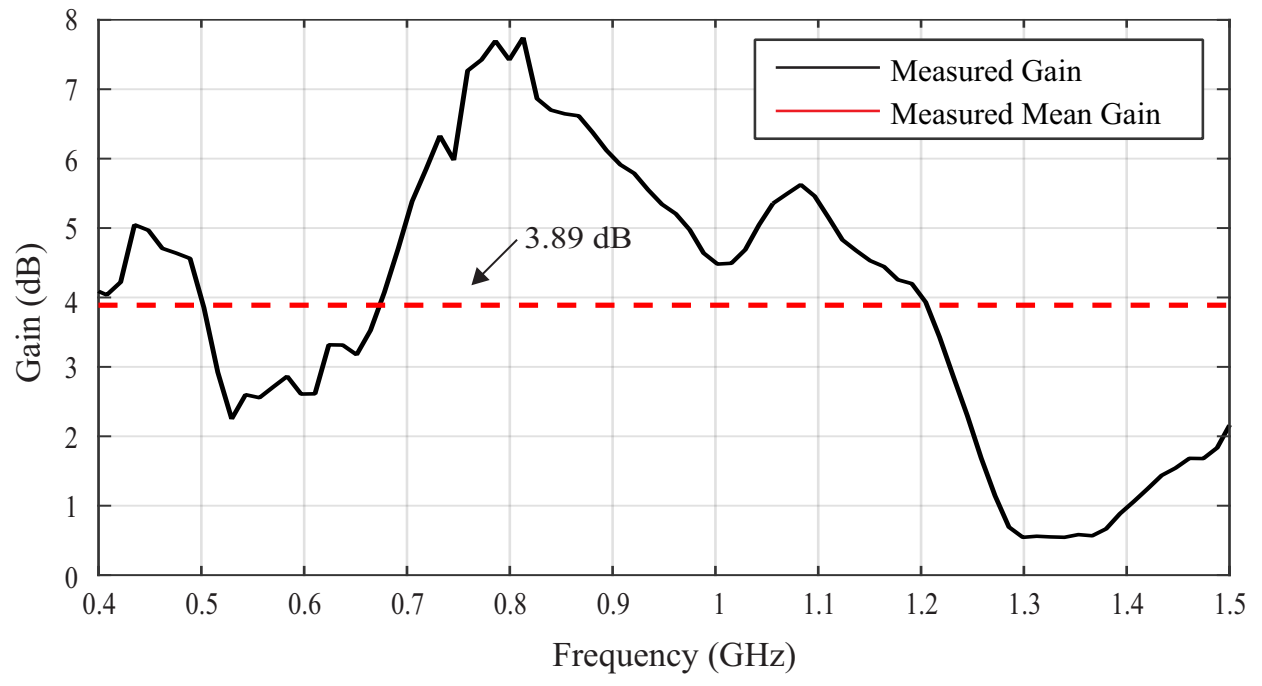

Figure 13. Measured UHF sensor gain.

\subsection{PD Measurement}

The third test performed was the PD measurement using the experimental setup shown in Figure 14. The setup is composed of the UHF sensor; a coupling capacitor of $1000 \mathrm{pF}$; an inductor of $15 \mathrm{mH}$; a measuring impedance LDM- 5 and a digital PD measuring system LDS-6, both developed by Double Lemke; and an oil-filled acrylic chamber with electrodes for PD generation. The measurements were carried out using a Keysight oscilloscope DSO90604A with bandwidth of $6 \mathrm{GHz}$, sampling rate of $20 \mathrm{GSa} / \mathrm{s}$, rise time of 70 ps and four analog channels. To minimize attenuation of the UHF signal in the coaxial cable, high efficiency coaxial cables, model SPUMA 400-FR-01, with attenuation of $0.13 \mathrm{~dB} / \mathrm{m}$, were used. The procedure adopted for the PD measurement levels was defined according to the IEC 60270 standard [1]. 


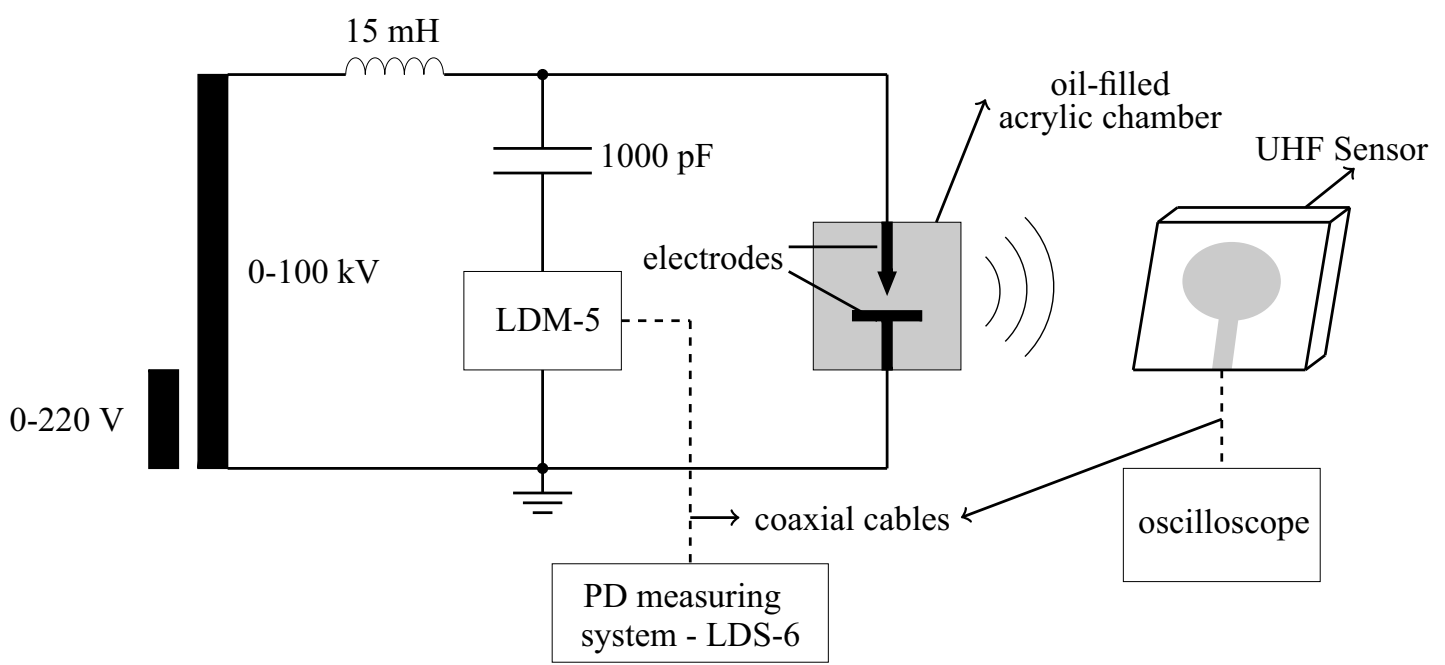

Figure 14. Measurement setup used for PD detection.

In order to produce the PD signals, a set of needle-plane electrodes and a polyamide disk (PA) were used. The PA disk was inserted between the electrodes and immersed in oil, in order to produce PD of low intensities. The Figures 15 and 16 show photographs of the measurement setup and the electrodes used for the PD production, respectively.

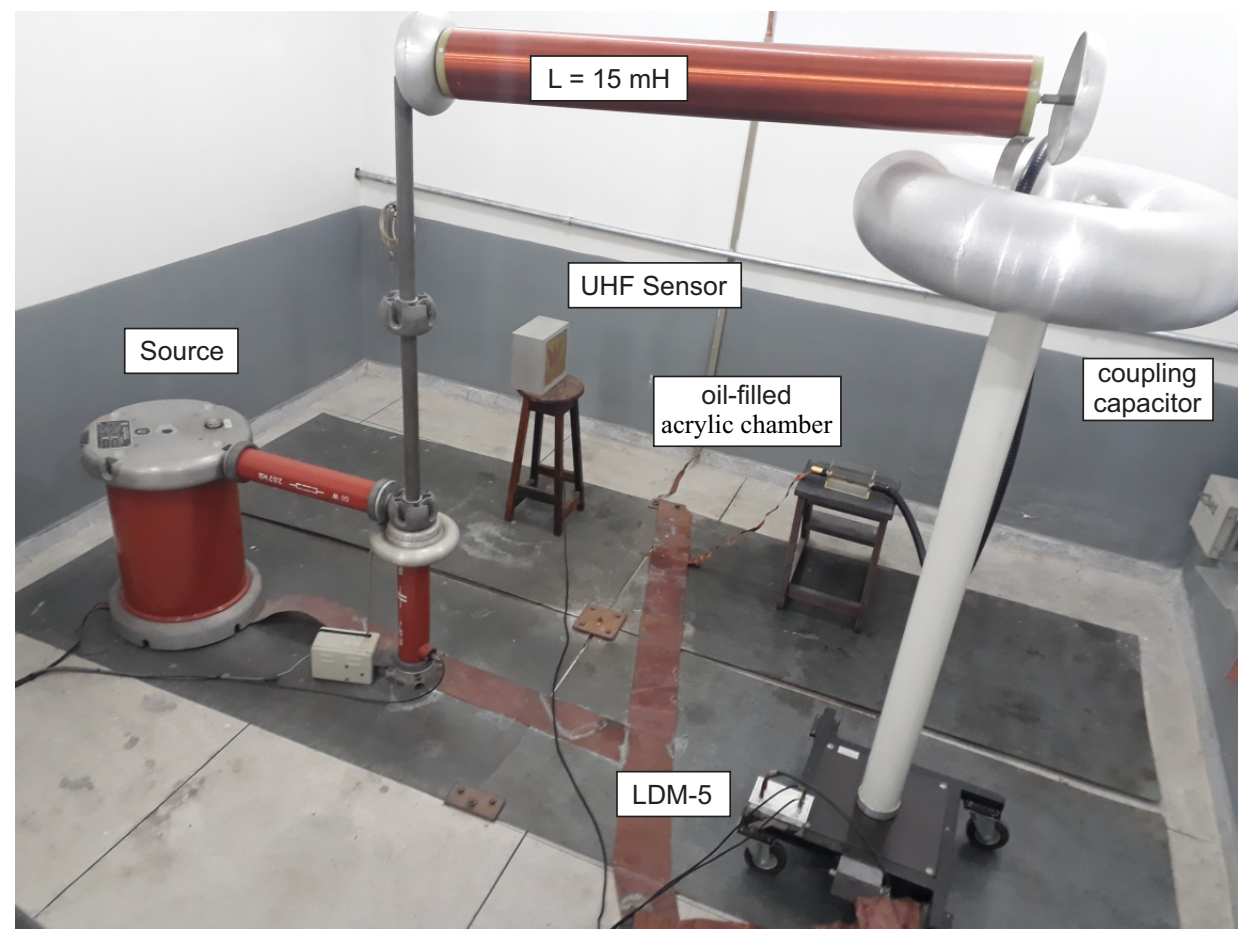

Figure 15. Photograph of the PD measurement setup.

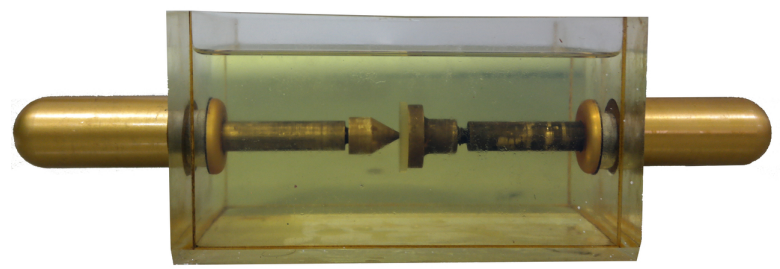

Figure 16. Photograph of the electrodes used for the PD production. 
With the measurement setup used, it was possible to obtain PD levels within a wide range, depending on the applied voltage level. Figure 17 shows, in the form of a correlation plot, the measured apparent charge of the PD pulses and the voltage obtained on the UHF sensor. After several tests, it was verified that the UHF sensor was able to identify PD signals of $35 \mathrm{pC}$ at a distance of $1 \mathrm{~m}$ from the PD source. Higher levels of up to thousands of picocoulombs were also obtained.

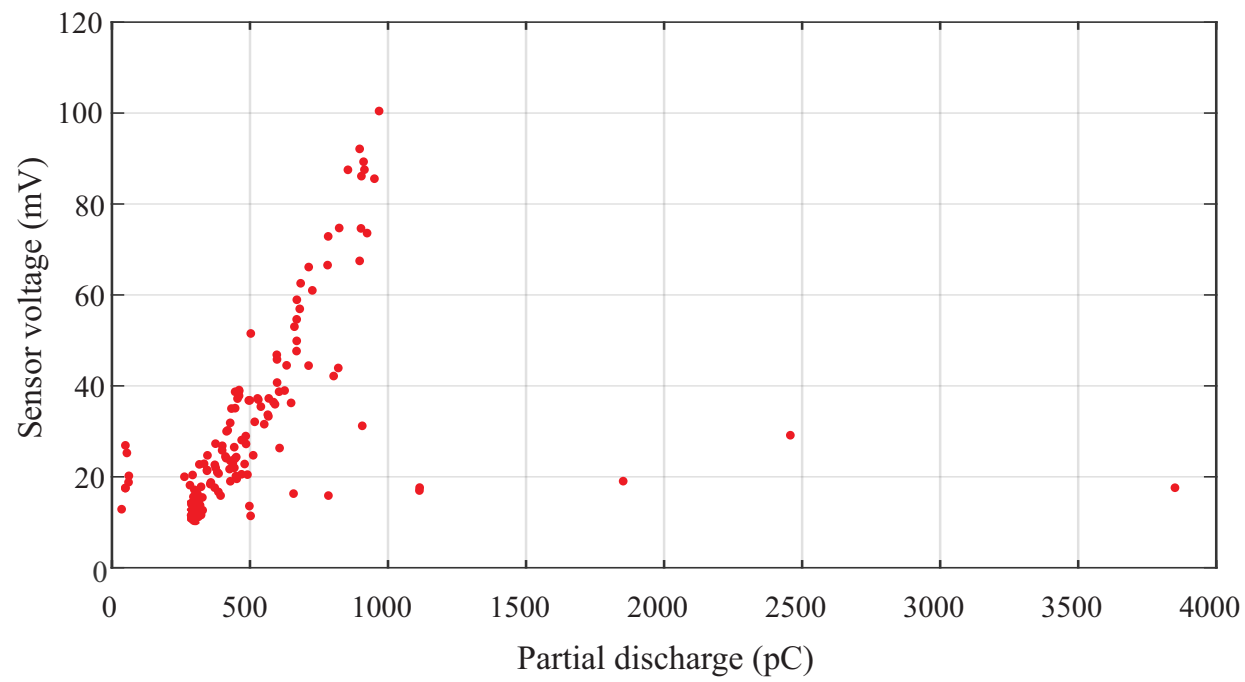

Figure 17. Correlation between the PD signal detected by the UHF sensor and the IEC 60270 standard method for the distance of $1 \mathrm{~m}$ between the UHF sensor and the PD source.

To illustrate a signal obtained by the UHF sensor, in Figure 18, a signal measured on the sensor and the same signal measured directly on the measuring impedance device are shown. As can be seen, the UHF signal is clearly distinguishable from the white noise present in the measurement and it has a typical PD shape, with a pulse shorter than the electrical signal obtained in the measuring impedance. Furthermore, it is observed that the UHF signal presented a time shift due to the signal propagation velocity to the UHF sensor, which was higher than the one noticed in the IEC 60270 standard setup.

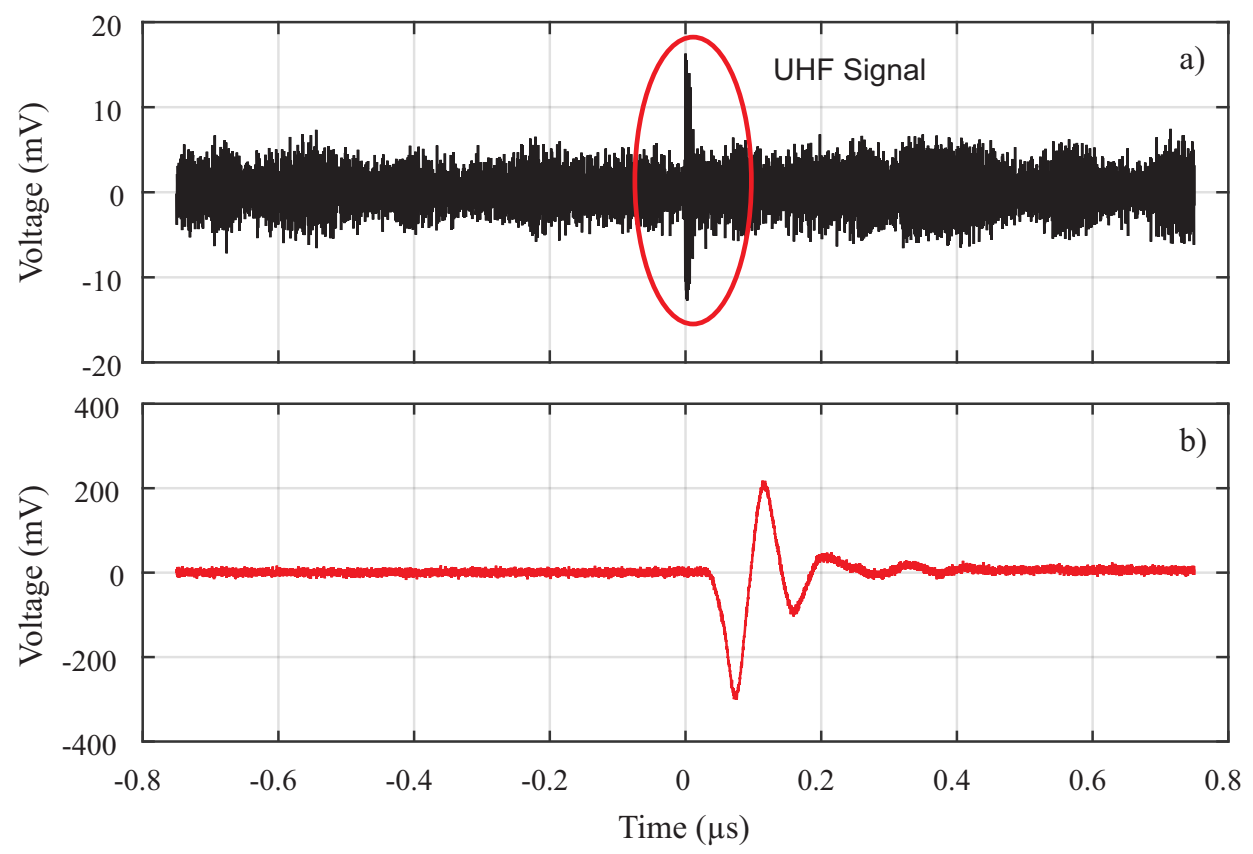

Figure 18. Comparison between the PD signal detected by (a) the UHF sensor and (b) the IEC 60270 standard method. 


\section{Discussion}

From the obtained results, some considerations can be made about the research developed in this paper.

First, the bio-inspired antenna was originally designed to obtain the reflection coefficient below $-10 \mathrm{~dB}$. However, as a result of the electromagnetic shielding effect caused by the aluminum enclosure, there was a reduction in the coefficient to approximately $-5 \mathrm{~dB}$. As discussed previously, this reduction in the signal transmission capacity is a known effect, since the sensor aluminum enclosure creates a coupling effect that interferes with the microstrip patch. However, a limit of $-5 \mathrm{~dB}$ in the reflection coefficient for the definition of the antenna bandwidth is sufficient for the most applications, since it allows transmission of approximately $70 \%$ of the power signal. In other studies, such as References [46] and [47], antennas with an even higher coefficient of reflection, in the order of $-3.5 \mathrm{~dB}$, were satisfactory for PD detection. Therefore, the sensor aluminum enclosure presented more advantages, especially the electromagnetic shielding, than disadvantages.

Second, the UHF sensor has demonstrated its effectiveness for PD detection in power transformers. The detected sensitivity for PD levels higher than $35 \mathrm{pC}$ is satisfactory, since commissioning tests allow PD levels of up to $200 \mathrm{pC}$ during a 1 minute overpotential test at 1.6 times the normal operating voltage, according to the procedures established in the IEC 60076 standard [48]. In addition, according to Reference [49], depending on the voltage and size of the transformer, levels up to $500 \mathrm{pC}$ are acceptable for normal operating voltage. Therefore, the UHF sensor developed in this research has shown satisfactory sensitivity for the expected application.

Finally, it can be affirmed that the methodology for the development of a UHF sensor for power transformers with a bio-inspired microstrip antenna is very promising, since the developed UHF sensor was demonstratively effective. One of the advantages of this type of sensor is its easy manufacturing and low cost, with the possibility of using other bio-inspired shapes to optimize one or more parameters of the sensor. Moreover, these advantages are associated with protection against corrosion guaranteed by the epoxy coating and the mechanical strength produced by the aluminum enclosure of the sensor. In this way, the use of the sensor against dielectric windows is guaranteed for the lifetime of the transformer.

\section{Conclusions}

In this work, a step-by-step procedure was presented for the design of a UHF sensor for use in dielectric windows of power transformers. Three main contributions were presented. Firstly, we have the development of a UHF sensor with four main parts: (1) one microstrip antenna with bio-inspired technology, to capture the UHF signal radiated from PD sources; (2) an epoxy coating, which provides protection against corrosion, mechanical support, and high temperature tolerance; and (3) an electromagnetic shield, in order to guarantee immunity from external noise. The developed sensor has an average gain of $3.89 \mathrm{~dB}$ and it demonstrated its effectiveness for the detection of PD signals with apparent charge values higher than $35 \mathrm{pC}$. In addition, it is designed to have a lifetime compatible with that of power transformers.

The second main contribution was the detailed analysis of the effect of electromagnetic shielding on the parameters of microstrip antennas. After analysis, it was found that a distance of at least $10 \mathrm{~cm}$ was required between the evaluated antenna ground plane and any metal structure to minimize bandwidth losses.

The third main contribution was the methodology, which was demonstrated as being very effective. With this, other UHF sensors for use in electrical equipment can be developed using the same methodology, with the possibility of using other bio-inspired shapes to optimize one or more of the sensor's parameters. 
Author Contributions: L.A.M.M.N. developed the idea of the UHF sensor and wrote the article. G.V.R.X. designed the bioinspired antenna. M.V.D.A. carried out the simulations to validate the results. The measuring setup and the experiments were performed by L.A.M.M.N., G.V.R.X., M.V.D.A., C.C.R.A. and A.J.R.S.; E.G.C. provided valuable suggestions and guidance for the research. All authors acknowledge and accept the responsibility of the research conducted and presented in this article.

Funding: This research received no external funding.

Acknowledgments: The authors want to acknowledge the Postgraduate Program in Electrical Engineering (PPgEE) of the Universidade Federal de Campina Grande (UFCG), the Coordination for the Improvement of Higher Level Education Personnel (CAPES), and the National Council for Technological and Scientific Development (CNPq).

Conflicts of Interest: The authors declare no conflict of interest.

\section{References}

1. International Electrotechnical Commission (IEC). IEC 60270, High-Voltage Test Techniques: Partial Discharge Measurements; IEC: Geneve, Switzerland, 2000.

2. Lundgaard, L. Partial discharge. XIV. Acoustic partial discharge detection-practical application. IEEE Electr. Insul. Mag. 1992, 8, 34-43. [CrossRef]

3. Markalous, S.M.; Tenbohlen, S.; Feser, K. Detection and location of partial discharges in power transformers using acoustic and electromagnetic signals. IEEE Trans. Dielectr. Electr. Insul. 2008, 15, 1576-1583. [CrossRef]

4. Deng, J.; Xiao, H.; Huo, W.; Luo, M.; May, R.; Wang, A.; Liu, Y. Optical fiber sensor-based detection of partial discharges in power transformers. Opt. Laser Technol. 2001, 33, 305-311. [CrossRef]

5. Schwarz, R.; Muhr, M. Modern technologies in optical partial discharge detection. In Proceedings of the Annual Report-Conference on Electrical Insulation and Dielectric Phenomena, Vancouver, BC, Canada, 14-17 October 2007; pp. 163-166.

6. Sun, C.; Ohodnicki, P.R.; Stewart, E.M. Chemical sensing strategies for real-time monitoring of transformer oil: A review. IEEE Sens. J. 2017, 17, 5786-5806. [CrossRef]

7. Siegel, M.; Beltle, M.; Tenbohlen, S.; Coenen, S. Application of UHF sensors for PD measurement at power transformers. IEEE Trans. Dielectr. Electr. Insul. 2017, 24, 331-339. [CrossRef]

8. Ishak, A.; Ishak, M.; Jusoh, M.; Dardin, S.S.; Judd, M. Design and optimization of UHF partial discharge sensors using FDTD modeling. IEEE Sens. J. 2017, 17, 127-133. [CrossRef]

9. Akbari, A.; Werle, P.; Akbari, M.; Mirzaei, H.R. Challenges in calibration of the measurement of partial discharges at ultrahigh frequencies in power transformers. IEEE Electr. Insul. Mag. 2016, 32, $27-34$. [CrossRef]

10. Mirzaei, H.; Akbari, A.; Gockenbach, E.; Miralikhani, K. Advancing new techniques for UHF PD detection and localization in the power transformers in the factory tests. IEEE Trans. Dielectr. Electr. Insul. 2015, 22, 448-455. [CrossRef]

11. Coenen, S.; Tenbohlen, S. Location of PD sources in power transformers by UHF and acoustic measurements. IEEE Trans. Dielectr. Electr. Insul. 2012, 19, 1934-1940. [CrossRef]

12. Tenbohlen, S.; Denissov, D.; Hoek, S.; Markalous, S. Partial discharge measurement in the ultra high frequency (UHF) range. IEEE Trans. Dielectr. Electr. Insul. 2008, 15, 1544-1552. [CrossRef]

13. Judd, M.; Li, Y.; Hunter, I. Partial discharge monitoring of power transformers using UHF sensors. Part I: Sensors and signal interpretation. IEEE Electr. Insul. Mag. 2005, 21, 5-14. [CrossRef]

14. Judd, M.; Li, Y.; Hunter, I. Partial discharge monitoring for power transformer using UHF sensors. Part 2: Field experience. IEEE Electr. Insul. Mag. 2005, 21, 5-13.

15. Hampton, B.F.; Meats, R.J. Diagnostic measurements at UHF in gas insulated substations. In IEE Proceedings C (Generation, Transmission and Distribution); IEC: Geneve, Switzerland, 1988; Volume 135, pp. 137-144.

16. Task Force 15/33.03.05. Partial Discharge Detection System for GIS: Sensitivity Verification for UHF Method and the Acoustic Method. ELECTRA 1999, 183, 75-87.

17. Rutgers, W.; Fu, Y. UHF PD-detection in a power transformer. In Proceedings of the 10th International Symposium on High Voltage Engineering, Montreal, QC, Canada, 25-29 August (1997); pp. $219-222$.

18. Working Group A2.27. Recommendations for condition monitoring and condition assessment facilities for transformers. Electra 2008, 237, 48-57. 
19. Judd, M. Locating Partial Discharges in Power Transformers. In Proceedings of the 10th Euro TechCon, Warwick, UK, 7-9 November 2011.

20. Zhang, Y.; Lazaridis, P.; Abd-Alhameed, R.; Glover, I. A compact wideband printed antenna for free-space radiometric detection of partial discharge. Turkish J. Electr. Eng. Comput. Sci. 2017, 25, 1291-1299. [CrossRef]

21. Li, T.; Rong, M.; Zheng, C.; Wang, X. Development simulation and experiment study on UHF partial discharge sensor in GIS. IEEE Trans. Dielectr. Electr. Insul. 2012, 19, 1421-1430. [CrossRef]

22. Yang, F.; Peng, C.; Yang, Q.; Luo, H.; Ullah, I.; Yang, Y. An UWB Printed Antenna for Partial Discharge UHF Detection in High Voltage Switchgears. Prog. Electromagn. Res. 2016, 69, 105-114. [CrossRef]

23. Zachariades, C.; Shuttleworth, R.; Giussani, R.; Loh, T.H. A Wideband Spiral UHF Coupler with Tuning Nodules for Partial Discharge Detection. IEEE Trans. Power Deliv. 2018. [CrossRef]

24. Zhang, Y.; Glover, I. Design of an ultrawideband VHF/UHF antenna for partial discharge detection. In Proceedings of the 2014 IEEE International Conference on Signal Processing, Communications and Computing (ICSPCC), Guilin, China, 5-8 August 2014; pp. 487-490.

25. Ahmed, O.M.H.; Sebak, A.R. A Novel Maple-Leaf Shaped UWB Antenna with a 5. 0-6. 0 GHz Band-Notch Characteristic. Prog. Electromagn. Res. 2009, 11, 39-49. [CrossRef]

26. Serres, A.J.R.; de Freitas Serres, G.K.; da Silva Júnior, P.F.; Freire, R.C.S.; do Nascimento Cruz, J.; de Albuquerque, T.C.; Oliveira, M.A.; da Fonseca Silva, P.H. Bio-Inspired Microstrip Antenna. In Trends in Research on Microstrip Antennas; InTech: London, UK, 2017.

27. Silva, P., Jr.; Freire, R.; Serres, A.; Silva, P.; Silva, J. Wearable textile bioinspired antenna for 2G, 3G, and 4G systems. Microw. Opt. Technol. Lett. 2016, 58, 2818-2823. [CrossRef]

28. Ahmed, O.M.H.; Sebak, A.R. Numerical and Experimental Investigation of a Novel Ultrawideband Butterfly Shaped Printed Monopole Antenna with Bandstop Function. Prog. Electromagn. Res. 2011, 18, 111-121. [CrossRef]

29. Ebnabbasi, K. A Bio-Inspired Printed-Antenna Transmission-Range Detection System [Education Column]. IEEE Antennas Propag. Mag. 2013, 55, 193-200. [CrossRef]

30. Li, J.; Wang, P.; Jiang, T.; Bao, L.; He, Z. UHF stacked Hilbert antenna array for partial discharge detection. IEEE Trans. Antennas Propag. 2013, 61, 5798-5801. [CrossRef]

31. Li, J.; Jiang, T.; Wang, C.; Cheng, C. Optimization of UHF Hilbert antenna for partial discharge detection of transformers. IEEE Trans. Antennas Propag. 2012, 60, 2536-2540.

32. Yao, C.; Chen, P.; Huang, C.; Chen, Y.; Qiao, P. Study on the application of an ultra-high-frequency fractal antenna to partial discharge detection in switchgears. Sensors 2013, 13, 17362-17378. [CrossRef] [PubMed]

33. Wang, Y.; Wang, Z.; Li, J. UHF Moore fractal antennas for online GIS PD detection. IEEE Antennas Wirel. Propag. Lett. 2017, 16, 852-855. [CrossRef]

34. Liu, B.; An, J.D.; Zhang, W.D.; Xu, Y.L. A Design of Multi-Band UHF Sensor for Partial Discharge Detection. Applied Mechanics and Materials; Trans Tech Publishers: Zurich, Switzerland, 2013; Volume 394, pp. 435-440.

35. Liu, J.; Zhang, G.; Dong, J.; Wang, J. Study on miniaturized UHF antennas for partial discharge detection in high-voltage electrical equipment. Sensors 2015, 15, 29434-29451. [CrossRef] [PubMed]

36. Zhang, X.; Cheng, Z.; Gui, Y. Design of a new built-in UHF multi-frequency antenna sensor for partial discharge detection in high-voltage switchgears. Sensors 2016, 16, 1170. [CrossRef] [PubMed]

37. Haddad, A.; Warne, D.F. Advances in High Voltage Engineering; IEC: Geneve, Switzerland, 2004; Volume 40.

38. Judd, M.; Pryor, B.; Kelly, S.; Hampton, B. Transformer monitoring using the UHF technique. In Proceedings of the Eleventh International Symposium on High Voltage Engineering, London, UK, $23-27$ August 1999; Volume 5, pp. 362-365.

39. De Kock, N.; Coric, B.; Pietsch, R. UHF PD detection in gas-insulated switchgear-suitability and sensitivity of the UHF method in comparison with the IEC 270 method. IEEE Electr. Insul. Mag. 1996, 12, 20-26. [CrossRef]

40. Coenen, S.; Tenbohlen, S.; Markalous, S.; Strehl, T. Sensitivity of UHF PD measurements in power transformers. IEEE Trans. Dielectr. Electr. Insul. 2008, 15, 1553-1558. [CrossRef]

41. Liu, M.; Li, Z. An Online UHF PD Monitoring System for Power Transformer and Its Applications. In Proceedings of the 2010 Asia-Pacific Power and Energy Engineering Conference, Chengdu, China, 28-31 March 2010; pp. 1-4.

42. Lopez-Roldan, J.; Tang, T.; Gaskin, M. Optimisation of a sensor for onsite detection of partial discharges in power transformers by the UHF method. IEEE Trans. Dielectr. Electr. Insul. 2008, 15, 1634-1639. [CrossRef] 
43. Haraz, O.; Sebak, A.R. UWB antennas for wireless applications. In Advancement in Microstrip Antennas with Recent Applications; InTech: London, UK, 2013.

44. Ballanis, C.A. Antenna Theory Analysis and Design; John Willey and Son's Inc.: Hoboken, NJ, USA, 2005.

45. Luo, H.; Cheng, P.; Liu, H.; Kang, K.; Yang, F.; Liu, K. Research on the UHF microstrip antenna for partial discharge detection in high voltage switchgear. In Proceedings of the 2016 IEEE 11th Conference on Industrial Electronics and Applications (ICIEA), Hefei, China, 5-7 June 2016; pp. 2273-2276.

46. Li, J.; Jiang, T.; Cheng, C.; Wang, C. Hilbert fractal antenna for UHF detection of partial discharges in transformers. IEEE Trans. Dielectr. Electr. Insul. 2013, 20, 2017-2025. [CrossRef]

47. Sarkar, B.; Mishra, D.; Koley, C.; Roy, N. Microstrip patch antenna based UHF sensor for detection of partial discharge in high voltage electrical equipments. In Proceedings of the Annual IEEE India Conference (INDICON), Pune, India, 11-13 December 2014; pp. 1-6.

48. International Electrotechnical Commission (IEC). IEC 60076-1, Power Transformers-Part 1: General; IEC: Geneve, Switzerland, 2011.

49. Wang, M.; Vandermaar, A.J.; Srivastava, K.D. Review of condition assessment of power transformers in service. IEEE Electr. Insul. Mag. 2002, 18, 12-25. [CrossRef]

(C) 2019 by the authors. Licensee MDPI, Basel, Switzerland. This article is an open access article distributed under the terms and conditions of the Creative Commons Attribution (CC BY) license (http:/ / creativecommons.org/licenses/by/4.0/). 